\title{
Alterações post-mortem em tambaqui (Colossoma macropomum) conservados em gelo
}

\author{
Post-mortem alterations in tambaqui (Colossoma macropomum) stored in ice
}

\author{
Neiva Maria de Almeida ${ }^{{ }^{*}}$ Gilvan Machado Batista ${ }^{2}$ Makie Kodaira $^{3}$ \\ Edson Lessi ${ }^{4}$
}

\section{RESUMO}

Este estudo apresenta a avaliação da qualidade de tambaqui (Colossoma macropomum) conservado em gelo. Foi determinado o tempo de vida útil por meio de avaliações sensoriais e análises de $\mathrm{pH}$ e bases voláteis totais (N-BVT) no músculo. A avaliação sensorial mostrou que os exemplares permaneceram com qualidade especial (Classe A) durante o período de 22 dias e com boa qualidade (Classe B) até 40 dias. A prova de degustação do peixe cozido mostrou que os exemplares permaneceram com qualidade especial (Classe A) durante o período de 31 dias, mantendo-se na Classe $B$ por até 40 dias. $\mathrm{O}$ pH e o $\mathrm{N}$-BVT do músculo aumentaram regularmente com o tempo de estocagem, mostrando-se como índices adequados para determinar a qualidade do pescado. O extenso período em condições de consumo, 43 dias, permite que a espécie seja comercializada, entre camadas de gelo, no mercado nacional e internacional.

Palavras-chave: conservação em gelo, Colossoma macropomum, peixe de água doce.

\section{ABSTRACT}

This study evaluates the quality of an Amazonian fish tambaqui (Colossoma macropomum), when stored in ice. Its shelf life was determined using sensory evaluations, $\mathrm{pH}$ and Total Volatile Bases (N-TVB) analysis of the muscle. The sensory evaluation showed that the samples retained special quality (Class A) for 22 days and good quality (Class B) for up to 40 days. The tasting session of cooked fish showed that the samples retained special quality (Class A) for 31 days and the Class $B$ lasted for 40 days. The $\mathrm{pH}$ and $\mathrm{N}$-TVB of the muscle increased regularly throughout the storage time, showing their suitability to determine the quality of the fishing. The long storage time, 43 days, allows the fish to be commercialized on ice on the national and international market.

Key words: storage on ice, Colossoma macropomum, freshwater fish.

\section{INTRODUÇÃO}

A produção mundial de pescado em 2003 foi de 132 milhões de toneladas. Desse total, a aqüicultura contribuiu com 48,4 milhões de toneladas (FAO, 2003). O Amazonas se destaca em primeiro lugar na produção extrativista de água doce, com 28,0\% do total produzido no Brasil, porém a contribuição para a aqüicultura é pequena, tendo produzido 837 toneladas no ano de 2000 (MMA, IBAMA, CEPENE, 2003). A participação do tambaqui (Colossoma macropomum) na produção total de pescado vem diminuindo ao longo dos anos, passando de 10,8\% em 1994 para 6,3\% em 1997, apesar de ser uma espécie nativa, que desperta a preferência dos consumidores e atinge excelente valor de mercado. O tambaqui é uma das espécies que mais desperta interesse para a piscicultura no Brasil (GRAEF, 1995).

\footnotetext{
${ }^{1}$ Departamento de Tecnologia Rural, CFT, Univerdiade Federal da Paraíba, campus III, Cidade Universitária, 58220-000, Bananeiras, PB, Brasil. E-mail: neivaa@yahoo.com.

${ }^{2}$ Departamento de Bromatologia, Faculdade de Farmácia, Faculdades Nilton Lins, Parque das Laranjeiras, 3259, 69058-040, Manaus, AM, Brasil. E-mail: gilvan.mb@ig.com.br.

${ }^{3}$ Universidad Central de Venezuela (UVC), Ciudad Universitaria, Los Chaguaramos, Caracas, Venezuela, Apartado postal 1050. Email: kodaira@cantv.net.

${ }^{4}$ Centro de Processamento em Tecnologia de Alimentos, Instituto Nacional de Pesquisa da Amazônia-INPA. Avenida André Araújo, 2936, 69083-000, Jardim Petrópolis, Manaus, AM, Brasil. E-mail: elessi@inpa.gov.br.

*Autor para correspondência.
} 
A qualidade sensorial do pescado depende de muitos processos, os quais são governados por mecanismos bioquímicos, químicos e microbiológicos A perda de frescor do pescado refrigerado é o reflexo da atividade desses processos (STONE \& SIDEL, 1993). O pH final do pescado após a sua morte está relacionado com a quantidade de glicogênio disponível nesse momento. A diminuição do pH é conseqüência da conversão do glicogênio em ácido lático (CONTRERAS-GUZMÁN, 1994).

O pescado refrigerado é deteriorado pela ação enzimática e bacteriana, resultando na produção de compostos nitrogenados, sendo os mais freqüentes a trimetilamina, a amônia e os ácidos voláteis. O teor dessas substâncias é medido pela determinação das Bases Voláteis Totais (N-BVT), que aumentam em função da deterioração do produto (HUSS, 1988).

Apesar de já existirem estudos anteriores de qualidade em tambaqui efetuados por pesquisadores da Venezuela, existe ainda a necessidade de outros estudos em tambaqui especificamente produzido pela piscicultura em Manaus, devido à particularidade de 0 transporte do pescado da fazenda até o ponto de comercialização ser realizado em caixa de isopor entre camadas de gelo. Assim, o estudo das alterações postmortem em tambaquis conservados em gelo, produzidos pela piscicultura, justifica-se plenamente dado o desenvolvimento da aqüicultura, a importância do pescado na região e já que, após a morte, o pescado sofre reações autolíticas no músculo que influenciam suas características organolépticas originais. Esta pesquisa teve o objetivo de determinar o tempo de vida útil de tambaqui produzido em piscicultura e conservado em gelo.

\section{MATERIAL E MÉTODOS}

Exemplares de C. macropomum procedentes de tanques de engorda do "Sítio dos Gaúchos”, Manaus-AM, foram capturados com rede de arrasto e sacrificados em água resfriada, colocados em gelo imediatamente após a morte, em uma proporção de 2:1 gelo/peixe. Em seguida, foram transportados em caixa de isopor ao laboratório da Coordenação de Pesquisas em Tecnologia de Alimentos (CPTA) do Instituto Nacional de Pesquisa da Amazônia (INPA). O gelo utilizado durante o experimento foi fabricado no laboratório da CPTA, em condições adequadas de potabilidade da água utilizada. Foram utilizados 87 exemplares, com peso médio de 2,5kg e comprimento médio de $47,9 \mathrm{~cm}$. A determinação da composição centesimal, pH e N-BVT, foi realizada de acordo com as “Normas Analíticas do Instituto Adolfo Lutz” (1985).
As avaliações sensoriais físicas foram realizadas no primeiro dia do experimento e a cada 48 horas. Para isso, três exemplares de tambaqui foram analisados por painelistas treinados, considerando os aspectos externos e internos do peixe como cor, odor, textura, principalmente das guelras, e integridade dos órgãos internos (BURGUES et al., 1967). Na prova de degustação, os painelistas avaliaram odor, sabor e textura, baseados na tabela da Torry Research-Station Escócia, (UK) (BURGUES et al., 1967), desenvolvida para avaliação de bacalhau cozido, com algumas modificações para adequá-la aos propósitos deste trabalho e à tabela utilizada pela FAO (FAO/DANIDAMoçambique, 1987). A classificação baseou-se em cada característica analisada, sendo dividida em quatro categorias: A, B, C e rejeitável.

O tratamento estatístico da avaliação sensorial física e as determinações de $\mathrm{pH}$ e N-BVT foram ajustados por regressão linear simples. Os valores do teste de degustação foram ajustados pela equação polinomial e com auxílio do software ORIGIN 5.0 (2000).

\section{RESULTADOS E DISCUSSÃO}

Os tambaquis em estudo apresentam 17,0\% de proteína e 7,6\% para lipídios totais, sendo considerados gordos (ACKMAN, 1989).

$\mathrm{Na}$ avaliação sensorial do pescado cru, as primeiras alterações se manifestaram pelo aparecimento de maior quantidade de muco na região das brânquias e por ligeiras deformações na textura, provocadas pelo acondicionamento no gelo. Entre 19 e 25 dias, observou-se odor forte na região da cabeça, guelras avermelhadas e presença de muco viscoso. A região do abdômen apresentava tonalidade avermelhada, dando indícios de alteração. Porém, o intestino ainda estava íntegro, enquanto o fígado já mostrava início de decomposição. Com 40 dias de estocagem, observou-se ausência de cor normal e aparência limosa na pele. Os olhos estavam esbranquiçados, com derramamento de sangue, pupilas acinzentadas e córneas com descoloração. A classificação de qualidade baseou-se na pontuação das características indicadas nas diferentes classes (Tabela 1). Os tambaquis apresentaram "qualidade especial” (classe A) até 22 dias de conservação em gelo; permaneceram em "boa qualidade” (classe B) até o 40ํdia; aos 43 dias, atingiram "qualidade de consumo corrente"; e, aos 49 dias em gelo, foram considerados pútridos por todos os analistas (Figura 1). Os tambaquis foram capturados e 
Tabela 1 - Tabela de avaliação sensorial baseada nas características do pescado cru.

\begin{tabular}{|c|c|c|c|c|c|c|c|c|}
\hline & Classe A & $*$ Pts & Classe B & Pts & Classe C & Pts & Rejeitável & Pts \\
\hline Guelras & $\begin{array}{l}\text { Cor vermelho- } \\
\text { vivo, muco } \\
\text { límpido e forte } \\
\text { odor de plantas } \\
\text { aquáticas. }\end{array}$ & 04 & $\begin{array}{l}\text { Cor vermelho- } \\
\text { pálido e } \\
\text { castanho- } \\
\text { avermelhado, } \\
\text { perda de odor de } \\
\text { plantas aquáticas. }\end{array}$ & 03 & $\begin{array}{l}\text { Castanho-escuro a } \\
\text { castanho- } \\
\text { amarelado, muco } \\
\text { leitoso, odor de } \\
\text { pão ou leite azedo. }\end{array}$ & 02 & $\begin{array}{l}\text { Cor branca, muco } \\
\text { granuloso, odores } \\
\text { de amônia, ácido } \\
\text { sulfúrico, odores } \\
\text { fecais. }\end{array}$ & 01 \\
\hline Olhos & $\begin{array}{l}\text { Claros, } \\
\text { brilhantes e } \\
\text { salientes, } \\
\text { pupilas negras } \\
\text { com matrizes } \\
\text { amareladas, } \\
\text { córneas } \\
\text { translúcidas. }\end{array}$ & 04 & $\begin{array}{l}\text { Encovados, } \\
\text { brancos, } \\
\text { nebulosos ou } \\
\text { amarelados, } \\
\text { pupilas com } \\
\text { algumas } \\
\text { descolorações, } \\
\text { córneas opacas. }\end{array}$ & 03 & $\begin{array}{l}\text { Encovados, } \\
\text { brancos, baços ou } \\
\text { sangüíneos, } \\
\text { pupilas leitosas ou } \\
\text { acinzentadas, } \\
\text { córneas côncavas } \\
\text { sujeitas a } \\
\text { descoloração. }\end{array}$ & 02 & $\begin{array}{l}\text { Muito sangüíneos } \\
\text { pupilas opacas e } \\
\text { cobertas de muco, } \\
\text { córneas } \\
\text { descoloradas ou } \\
\text { enrugadas. }\end{array}$ & 01 \\
\hline Pele & $\begin{array}{l}\text { Cor normal, } \\
\text { lustrosa e clara. }\end{array}$ & 04 & $\begin{array}{l}\text { Cor baça, sem } \\
\text { aparência limosa. }\end{array}$ & 03 & $\begin{array}{l}\text { Ausência de cor } \\
\text { normal e lustrosa, } \\
\text { estrutura muscular } \\
\text { visível. }\end{array}$ & 02 & $\begin{array}{l}\text { Descolorada em } \\
\text { avançado estado de } \\
\text { decomposição. }\end{array}$ & 01 \\
\hline Cheiro & $\begin{array}{l}\text { Típico de peixe } \\
\text { capturado } \\
\text { recentemente. }\end{array}$ & 04 & $\begin{array}{l}\text { Odor pouco } \\
\text { acentuado, } \\
\text { neutro. }\end{array}$ & 03 & $\begin{array}{l}\text { Ligeiramente } \\
\text { azedo ou rançoso, } \\
\text { mas não a } \\
\text { putrefação. }\end{array}$ & 02 & $\begin{array}{l}\text { Azedo, mau } \\
\text { cheiroso ou a } \\
\text { putrefação. }\end{array}$ & 01 \\
\hline Textura & $\begin{array}{l}\text { Escamas } \\
\text { brilhantes e } \\
\text { fortemente } \\
\text { aderidas, } \\
\text { nenhuma } \\
\text { deformação, } \\
\text { musculatura } \\
\text { firme e elástica, } \\
\text { especialmente } \\
\text { no abdômen. }\end{array}$ & 04 & $\begin{array}{l}\text { Com pouco } \\
\text { brilho, cor } \\
\text { ligeiramente } \\
\text { escura, ligeiras } \\
\text { deformações ou } \\
\text { mutilações, } \\
\text { musculatura } \\
\text { firme não } \\
\text { elástica. }\end{array}$ & 03 & $\begin{array}{l}\text { Superfície rugosa, } \\
\text { escamas } \\
\text { aderentes, } \\
\text { algumas fendas, } \\
\text { musculatura mole. }\end{array}$ & 02 & $\begin{array}{l}\text { Superfície áspera, } \\
\text { muitas fendas, } \\
\text { musculatura } \\
\text { flácida; quando } \\
\text { apertada entre os } \\
\text { dedos, não torna à } \\
\text { posição inicial. }\end{array}$ & 01 \\
\hline $\begin{array}{l}\text { Órgãos } \\
\text { Internos }\end{array}$ & $\begin{array}{l}\text { Peritônio } \\
\text { íntegro. Parede } \\
\text { abdominal } \\
\text { íntegra.Rim } \\
\text { vermelho-vivo. } \\
\text { Fígado íntegro. }\end{array}$ & 04 & $\begin{array}{l}\text { Peritônio } \\
\text { oxidado (escuro). } \\
\text { Parede } \\
\text { abdominal com } \\
\text { início de } \\
\text { digestão. Rim } \\
\text { vermelho. Fígado } \\
\text { e intestino em } \\
\text { decomposição. }\end{array}$ & 03 & $\begin{array}{l}\text { Peritônio desfeito } \\
\text { (cor preta). Parede } \\
\text { abdominal } \\
\text { digerida e com } \\
\text { espinhas salientes. } \\
\text { Rim vermelho- } \\
\text { escuro. Fígado e } \\
\text { intestino } \\
\text { ligeiramente } \\
\text { desfeitos. }\end{array}$ & 02 & Escuros e desfeitos. & 01 \\
\hline Valor & $24-19$ & & $18-13$ & & $12-06$ & & Menor do que 06 & \\
\hline
\end{tabular}

$*$ Pts $=$ pontos

Fonte: FAO (1987); BURGESS (1967).

manejados adequadamente, tendo sido sacrificados em água resfriada e colocados em gelo imediatamente após a morte, ainda na margem do viveiro. Essa metodologia de sacrifício provavelmente influenciou o tempo de vida útil. KODAIRA (1992) observou, em tambaqui proveniente de cultivo conservado em gelo, que as primeiras variações ocorreram entre 6 e 9 dias de estocagem. Entre 15 e 18 dias, os exemplares começaram a apresentar alterações nas paredes abdominais; fato que não se observou nesse estudo até 49 dias de estocagem. MARTINEZ-VALDIVIESO et al. (1998) observaram em “cachama híbrida”, cruzamento de tambaqui e pirapitinga (Piaractus branchypomus), um tempo de vida útil de 18 dias para mostra imediatamente resfriada a $0^{\circ} \mathrm{C}$. NaAmazônia, CASTELO (1992) e JESUS et al. (1990) trabalharam com peixes acondicionados em gelo e concluíram que a variação no tempo de vida útil das espécies estudadas depende das condições de captura e manejo. Enquanto JOSEPH et al. (1988), trabalhando com rohu (Labeo rohita) cultivado, observaram um tempo de vida útil de 15 dias, em exemplares conservado em gelo, NAIR et al. (1971) 


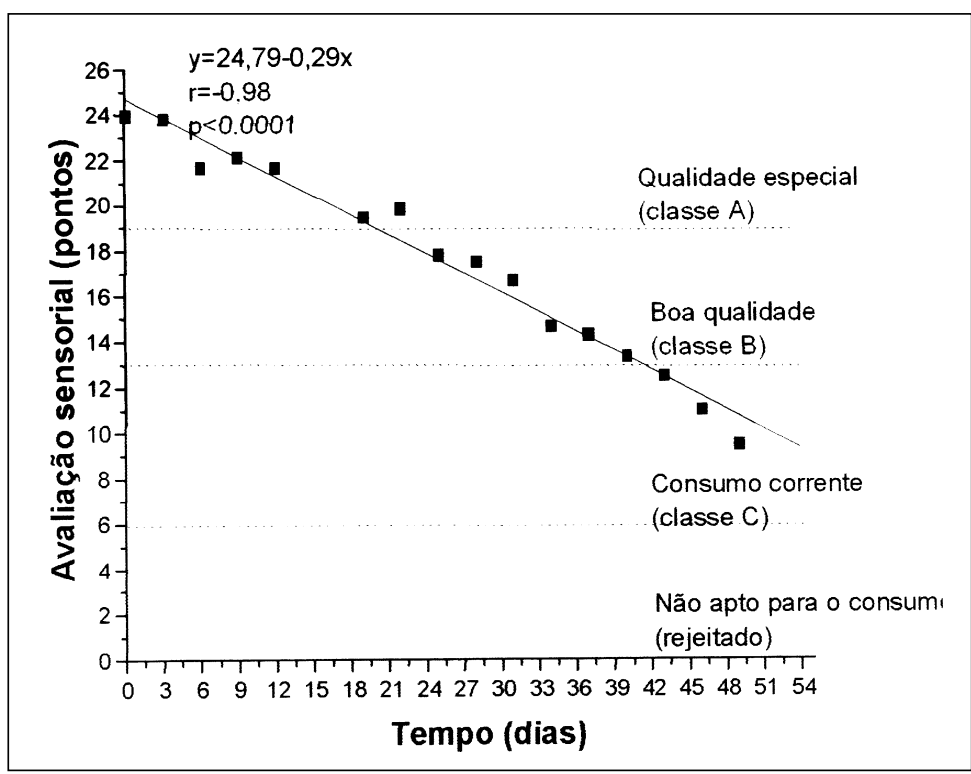

Figura 1 - Avaliação sensorial do tambaqui mantido em gelo.

relataram que o tempo de vida útil para carpa (Cirrhina mrigala) foi de 35 dias, quando estocadas em gelo.

$O$ teste de degustação pontuou os exemplares de tambaqui de acordo com as diferentes classes, segundo a tabela de avaliação utilizada (BURGUES et al., 1967) (Tabela 2). Esse teste mostrou que os tambaquis se mantiveram em "qualidade especial” até 31 dias de conservação em gelo, atingindo 10 pontos e permanecendo em "boa qualidade" até o $40^{\circ}$ dia de armazenagem. Aos 43 dias de conservação em gelo, atingiram "qualidade de consumo corrente" (Figura 2).

Os valores médios de $\mathrm{pH}$ variaram de 6,07 a 6,66 durante os 49 dias de estocagem (Figura 3). No início do experimento, o $\mathrm{pH}$ apresentou pequenas variações. No período de estocagem, entre 19 a 43 dias, foi observado aumento do $\mathrm{pH}$, coincidindo com os dados da avaliação sensorial das características físicas que mostraram, nesse período, uma acentuada perda da qualidade, passando o pescado da “qualidade B” para a “qualidade C”. Em pescado recém capturado, o $\mathrm{pH}$ tende à neutralidade. BELLO \& RIVAS (1992) mostraram, para tambaquis, conservados a $0^{\circ} \mathrm{C}$ e estressados pela captura, valores de pH de 6,69; 6,75 e 6,54. PEREZ et al. (2001) encontraram valor de $\mathrm{pH}$, no momento da captura, de 6,94 no híbrido de tambaqui e MARTINEZ-VALDIVIESO et al. (1998) observaram que o pH em "cachama híbrida" mostrou-se constante entre 6,4 e 6,6, quando a amostra era imediatamente resfriada em gelo. NAIR et al. (1971) relataram que o pH de carpa apresenta-se praticamente constante entre 6,3 e 6,5 durante 36 dias de estocagem em gelo.

O conteúdo total de compostos básicos voláteis em pescado é geralmente baixo nas primeiras etapas de armazenamento em gelo. Somente quando o pescado apresenta perda de qualidade, esse conteúdo aumenta rapidamente (HUSS, 1988). Os valores de NBVT no músculo de tambaqui apresentaram variação durante todo o período de estocagem (Figura 4). A medida inicial de N-BVT foi de 5,85mgN $100 \mathrm{~g}^{-1}$ em cerca de 6 horas, com pequena variação até o sexto dia de estocagem. Foi observado aumento de $100 \%$ no $13^{\circ}$ dia, quando o pescado era ainda de Classe A, segundo a análise sensorial. Seguiu-se um aumento gradual até

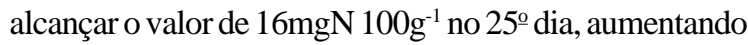
continuamente até o valor de 30mgN 100-1, aos 37 dias

Tabela 2 - Proposta de avaliação sensorial (degustação).

\begin{tabular}{|c|c|c|c|c|c|c|c|c|}
\hline & Classe A & *Pts & Classe B & Pts & Classe C & Pts & Rejeitável & Pts \\
\hline Odor & $\begin{array}{l}\text { Característico } \\
\text { de peixe fresco }\end{array}$ & 04 & $\begin{array}{l}\text { Perda de odor } \\
\text { fresco ou odor } \\
\text { neutro }\end{array}$ & 03 & $\begin{array}{l}\text { Odor doce ou } \\
\begin{array}{ll}\text { azedo } & \text { e/ou } \\
\text { estranho, }\end{array}\end{array}$ & 02 & $\begin{array}{l}\text { Odor amoniacal e } \\
\text { odor de alguns } \\
\text { sulfurosos }\end{array}$ & 01 \\
\hline Sabor & $\begin{array}{l}\text { Característico } \\
\text { de peixe fresco } \\
\text { ou adocicado }\end{array}$ & 04 & $\begin{array}{l}\text { Perda de sabor } \\
\text { de peixe fresco }\end{array}$ & 03 & $\begin{array}{l}\text { Sabor de peixe } \\
\text { ou ligeiro } \\
\text { sabor amargo } \\
\text { ou estranho, }\end{array}$ & 02 & $\begin{array}{l}\text { Sabor estranho e/ } \\
\text { ou forte }\end{array}$ & 01 \\
\hline Textura & Firme e elástica & 04 & $\begin{array}{l}\text { Firme, não- } \\
\text { elástico }\end{array}$ & 03 & $\begin{array}{l}\text { Ligeiramente } \\
\text { mole }\end{array}$ & 02 & Totalmente mole & 01 \\
\hline Valor & $12-10$ & & $09-07$ & & $06-03$ & & Menor do que 03 & \\
\hline
\end{tabular}

*Pts $=$ pontos

Fonte: FAO (1987); BURGESS (1967) 


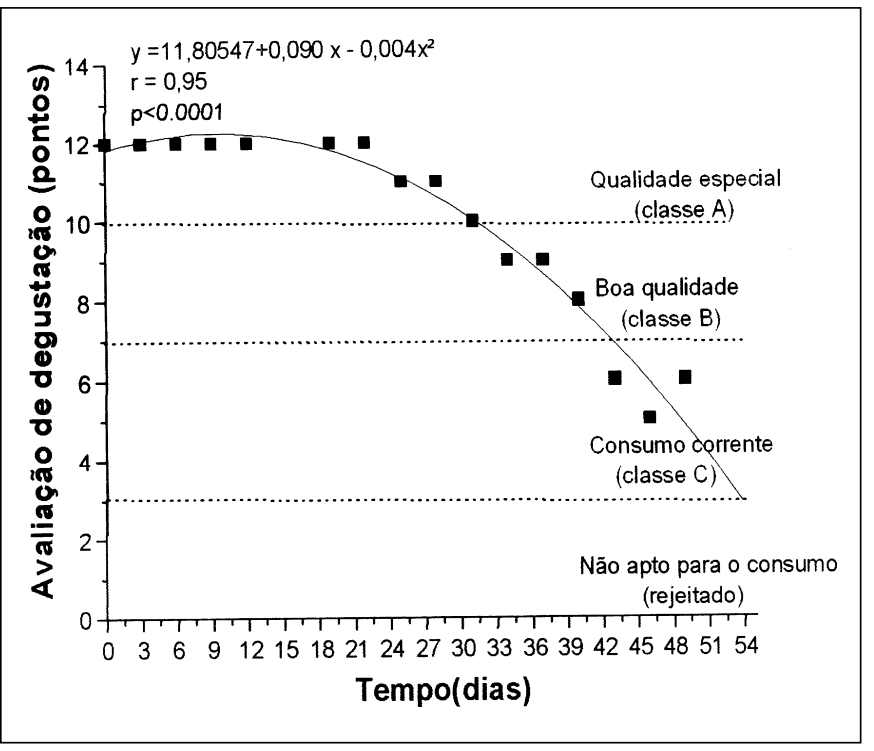

Figura 2 - Resultados da prova de degustação dos filés cozidos do tambaqui mantido em gelo.

de estocagem. Nesse momento, a avaliação sensorial indicava o início de qualidade "consumo corrente” (classe C). Aos 40 dias de estocagem, observou-se que

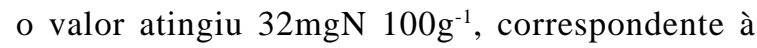
classificação de “consumo corrente”, de acordo com a avaliação física sensorial, e correspondente à "boa qualidade” na prova de degustação. O valor médio encontrado para N-BVT, após 37 dias de estocagem, já se encontrava dentro do limite estabelecido pelo

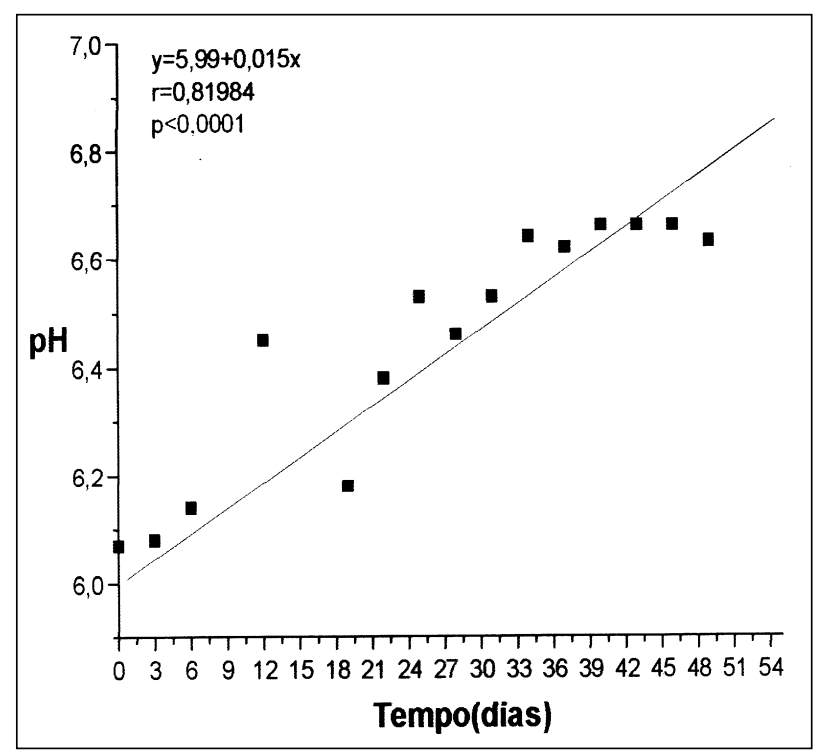

Figura 3 - Valores de pH no músculo do tambaqui mantido em gelo.
RIISPOA de 30-35mg N-BVT $100 \mathrm{~g}^{-1}$ para músculo de peixes (BRASIL, 1980). Ao completar 46 dias de estocagem, o valor médio foi de 35mgN $100 \mathrm{~g}^{-1}$; valor correspondente ao limite máximo indicado pela legislação, sendo este o período de menor pontuação na prova de degustação. KODAIRA (1992) encontrou pouca variação para N-BVT com valores iniciais de $13,33 \mathrm{mgN}^{100 \mathrm{~g}^{-1} \text { e de } 15,82 \mathrm{mgN}}$ $100 \mathrm{~g}^{-1}$ no $30^{\circ}$ dia de armazenamento, valores semelhantes aos relatados por BELLO \& RIVAS (1992), que relataram valores iniciais

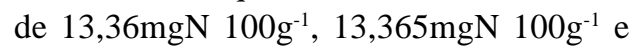
12,97mgN/100g. Por sua vez, MARTINEZVALDIVIESO et al. (1998) observaram vários tempos de retardamento do resfriamento da "cachama híbrida” e encontraram valores iniciais de 19,2mgN $100 \mathrm{~g}^{-1}$ e 20,3mgN 100g-1 ao final do $21^{\circ}$ dia de estocagem, em amostras imediatamente resfriadas em gelo. Entretanto, não é mencionado o método de captura e manejo do pescado. NAIR et al. (1971) observaram que os valores de N-BVT se mantiveram constantes até o $12^{\circ}$ dia de estocagem em gelo, seguidos de um rápido aumento.

\section{CONCLUSÕES}

De acordo com a avaliação sensorial física e de degustação, o tempo de vida útil de tambaqui foi de 43 dias de estocagem entre camadas de gelo. Esse período permite que essa espécie seja comercializada no mercado nacional e internacional em boas condições de consumo. A avaliação sensorial física e a prova de degustação, tal como apresentadas neste trabalho, podem ser utilizadas como critérios de avaliação de qualidade em tambaqui. Além disso, os valores de pH e das concentrações de bases voláteis totais podem ser considerados bons índices de avaliação de frescor, sendo e associados à avaliação sensorial e ao tempo de permanência do pescado em camadas de gelo.

\section{AGRADECIMENTOS}

À Coordenação de Aperfeiçoamento de Pessoal de Nível Superior (CAPES), pela concessão da bolsa de estudos e do suporte financeiro.

Ao Instituto Nacional de Pesquisas da Amazônia (INPA), pela concessão dos laboratórios da Coordenação de Pesquisas em Tecnologia de Alimentos. 


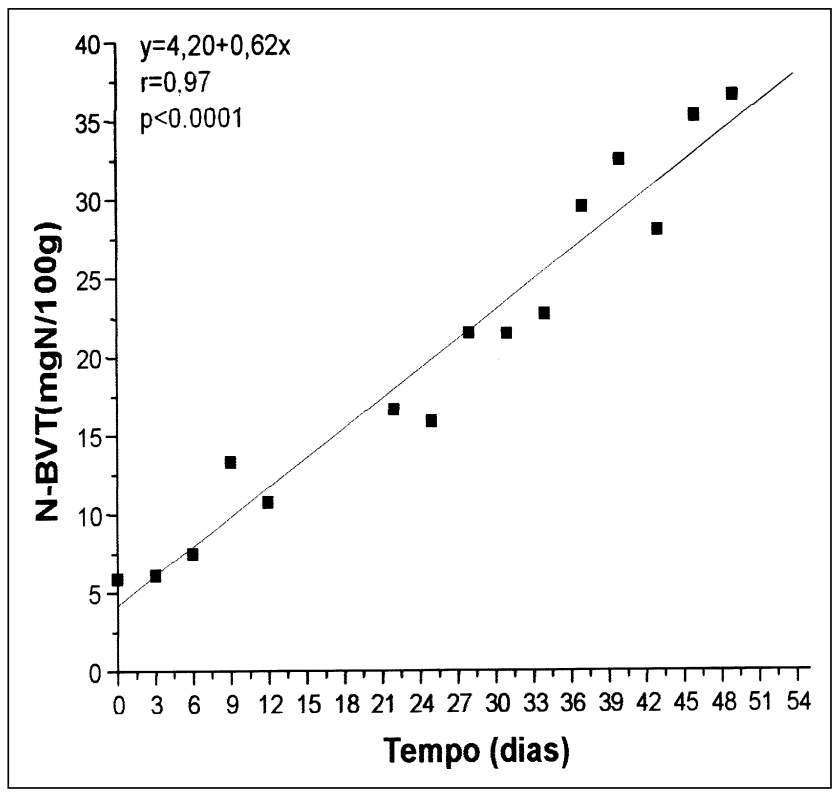

Figura 4 - Valores das bases voláteis totais - N-BVT- no músculo do tambaqui mantido em gelo.

\section{REFERÊNCIAS}

ACKMAN, R.G. Nutritional composition of fats in seafood. Progress in Food and Nutrition Science, v.13 p.161-241, 1989.

BELLO, R.A.; RIVAS, W.G. Evaluacion y aprovechamiento de la cachama (Colossoma macropomum) cultivada, como fuente de alimento. In: Organizacion de las Naciones Unidas para la Agricultura y la Alimentacion. Italy, Mexico: FAO, 1992. D.F, n.2, out, 113p.

BRASIL, Ministério da Agricultura, Pecuária e Abastecimento. Regulamento da Inspeção Industrial e Sanitária de Produtos de Origem Animal - RIISPOA. Brasília, 1980. $165 p$.

BURGESS, G.H.O. et al. Fish handling and processing. New York: Chemical, 1967. 389p.

CASTELO, F.P. Aproveitamento racional de pescado de água doce da Amazônia. Avaliação do frescor da matrinxã (Brycon sp) em gelo. Acta Amazonica. v.22, n.3, p.449-460, 1992.

CONTREAS-GUZMÁN, E.S. Bioquímica de pescados e derivados. Jaboticabal:FUNEP, 1994. 409p.

FAO/DANIDA. Curso de tecnologia e controle de qualidade de produtos de pesca. Moçambique, 1987. 55p. (Relatório).

FAO. World Review of Fisheries and Aquaculture, Fisheries Resources: Trends in Production, Utilization and trade, 2003. Acesso em: 03/10/2004. On line. Disponível em htpp://www.Fao.Org/docrep/003/x8002e04.htm.

GRAEF, E.W. As espécies de peixes com potencial para criação no Amazonas. In: VAL. A.L.; HONCZARY, A. Criando peixe na Amazônia. 19.ed. Manaus: INPA, 1995. p.29-43.

HUSS, H.H. El pescado fresco: su calidad y cambios de calidad. In:FAO. Manual de Capacitación Preparado por el Programa de Capacitación FAO/DANIDA en Tecnología Pesquera y Control de Calidad. Roma: FAO, 1988. V.29.

JESUS, R.S. et al. Deterioração do pescado de água doce da Amazônia. Qualidade dos jaraquis (Semaprochilodus spp) comercializado em Manaus, Am. Ciência e Tecnologia de Alimentos, v.10, n.2, p.216-230, 1990.

JOSEPH, J. et al. Studies on ice of cultured rohu (Labeo rohita). Fishery Technology, v.25, p.105-109, 1988.

INSTITUTO ADOLFO LUTZ, São Paulo. - Normas Analíticas do Instituto Adolfo Lutz. 3.ed. São Paulo: IMESP, 1985. V.1. p.21-54, 266.

MMA, IBAMA, CEPENE. Estatística da Pesca - Brasil, Grandes Regiões e Unidades da Federação, Tamandaré, Pernambuco. 2003. 96p.

KODAIRA, M. Manejo del pescado de águas continentales en condiciones de refrigeración. In: Informes Nacionales y Documentos Selecionados Presentados en la Cuarta Reunion del Grupo de Trabajo sobre Tecnologia Pesquera. Cartagena, Colombia: FAO, 1992. p.104-128. (N. 476 S).

MARTINEZ-VALDIVIESO, R. et al. Efecto del tiempo de retardo en la refrigeración sobre la estabilidad microbiologica de cachama durante su almacenamiento en hielo. In: CONGRESSO BRASILEIRO DE CIÊNCIA E TECNOLOGIA DE ALIMENTOS, 1998, Rio de Janeiro. Anais... Antonio de A. Figueiredo (Ed.). RJ: SBCTA, 1998. V.1, p.232-235.

NAIR, R.B. et al. Studies on chilled storage of fresh water fish I. Changes occurring during iced storage. Journal Food Science and Technology, v.8, p.53-56, 1971.

ORIGIN. Microcal Software. Origin Systems OSI, Version 5.0 Northampton, EUA, 2000. 26p.

PÉREZ, M. et al. Efecto de la temperatura de almacenamiento sobre los cambios post-mortem y frescura en híbridos de Cachama (Colossoma macropomum $\mathrm{x}$ Piaractus brachypomus) cultivados. Anales Venezolanos de Nutrición, v.14, n.2, p.53-59, 2001.

STONE, H.; SIDEL, J. Sensory evaluation practices. 2.ed. New York: Academic, 1993. 338p. 